\title{
Suplementação nutricional na produção de anticorpos séricos contra o vírus rábico em ovinos vacinados contra raiva
}

\section{Nutritional supplementation on production of sericos antibodies against the virus rabico in ovine vaccinated against rabies}

\author{
Sandra Cristina Genaro ${ }^{1 *}$; Paulo Eduardo Pardo; \\ Rogerio Giuffrida ${ }^{2}$; Neuza Maria Frazati-Gallina ${ }^{4}$
}

\begin{abstract}
Resumo
Esse estudo avaliou o efeito da suplementação do probiótico com ou sem zinco (Zn), adicionado à mistura mineral, na produção de anticorpos séricos contra o vírus rábico em ovinos vacinados com uma única dose de vacina. Quarenta e cinco ovinos machos, mestiços Santa Inês, com idade de 6 meses foram divididos aleatoriamente em 3 grupos (15 ovinos/grupo): Grupo controle (GC) recebeu 10 gramas de suplemento mineral/animal/dia, grupo probiótico (GP) recebeu 10 gramas de suplemento mineral adicionado 4 gramas de probiótico/animal/dia e grupo Probiótico e Zinco (GPZn) recebeu 10 gramas de suplemento mineral adicionado 4 gramas de probiótico e 14,4 mg de sulfato de zinco/ animal/dia adicionado ao probiótico. Os títulos individuais de anticorpos foram determinados por meio da técnica de soroneutralização baseado no Rapid Fluorescent Focus Inhibition Test (RFFIT) e no Fluorescent Inhibition Microtest (FIMT). Não houve diferenças estatísticas significativas entre as médias de concentrações séricas entre os grupos. Conclui-se que a administração de probióticos com ou sem zinco não melhora a resposta imune humoral antirrábica.
\end{abstract}

Palavras-chave: Anticorpos, raiva, ovinos

\begin{abstract}
This study evaluated the effect of probiotics supplementation with or without Zinc (Zn), added to the mineral mixture, in humoral immune response in sheep vaccinated with a single dose of rabies vaccines. Forty-five malecrossbred rams Santa Inês, aged 6 months were randomly divided into 3 groups (15 animals / group): Control group (CG) received 10 grams of mineral / animal / day, the probiotics group (GP) received 10 grams of mineral added 4 grams of probiotics / animal / day and Probiotics and Zinc group (GPZn) received 10 grams of mineral added 4 grams of probiotics and $14.4 \mathrm{mg}$ of zinc sulfate per animal per day added to the probiotics. The individual titles of neutralizing antibodies were determined using the technique of neutralization-based Rapid Fluorescent Focus Inhibition Test (RFFIT) and Fluorescent Inhibition Microtest (FIMT). There were no statistically significant differences between the mean serum concentrations between groups. It was concluded that the probiotics administration with or without zinc did not improve the immune humoral response of antibody rabies.
\end{abstract}

Key words: Antibody, rabies, sheep

\footnotetext{
${ }^{1}$ M.e em Ciência Animal, Docente, Universidade do Oeste Paulista, UNOESTE, Presidente Prudente, SP. E-mail: sgenaro@ unoeste.br

${ }^{2}$ Profs. Drs. da Universidade do Oeste Paulista, UNOESTE, Presidente Prudente, SP. E-mail: eduardopardo@unoeste.br; rgiuffrida@unoeste.br

${ }^{3}$ Dr. do Laboratório de Raiva, Instituto Butantan, São Paulo, SP. E-mail: nmfraza@butantan.gov

* Autor para correspondência
} 


\section{Introdução}

A raiva é uma enfermidade infecciosa viral aguda do sistema nervoso central dos mamíferos, onde no Brasil, o principal agente transmissor do vírus rábico para animais de fazenda, é o morcego hematófago Desmodusrotundus (SCHEFFER et al., 2007; BRASIL, 2009). Na América Latina, esta enfermidade vem causando um prejuízo da ordem de 30 milhões de dólares/ano e no Brasil, os prejuízos indiretos estão calculados em 22,5 milhões de dólares/ano (BRASIL, 2009; INSTITUTO PASTEUR, 2012b).

A vacinação é o melhor método de controle da raiva por ser efetiva e de baixo custo (ALBAS et al., 2006) e para que haja um estado imunitário suficiente para proteger indivíduos expostos ao risco de infecção, a Organização Mundial de Saúde (OMS) recomenda a avaliação da imunidade antirrábica pela titulação de anticorpos e considera um título igual ou maior que $0,5 \mathrm{UI} / \mathrm{mL}$ (WHO, 1992).

No Brasil, é comum ocorrer a ineficiência da imunidade na primovacinação das vacinas antirrábicas, liberadas e comercializadas, mesmo com seus valores antigênicos dentro dos parâmetros de normalidade segundo seus fabricantes (MARIA et al., 2009). Sendo assim, é necessário buscar alternativas para aumentar a eficácia da vacinação contra o vírus da raiva (FERREIRA et al., 2009).

Na Europa, América do Norte e Ásia, antibióticos e quimioterápicos usados como promotores de crescimento deixaram de ser utilizados na produção de bovinos de corte e leite, em virtude da possibilidade de acúmulo de resíduos nos produtos de origem animal (carne, leite e derivados), bem como no meio ambiente (TERRASSI et al., 2010). Com as restrições impostas pela União Europeia, os produtores europeus atualmente recorrem a um número limitado de promotores de crescimento e no Brasil, os produtos que foram utilizados no passado encontram-se atualmente proibidos como aditivos de rações (MENTEN, 2001).
Uma das estratégias para aumentar a resposta imunológica dos animais à imunidade induzida ou às infecções provocadas por vírus ou bactérias é o uso de adjuvantes, que tem revelado melhora na restauração da resposta imunitária e na potencialização de vacinas em relação a diversos agentes patógenos (RODRIGUES et al., 2005) como probióticos (ARENAS et al., 2009; FERREIRA et al., 2009) e/ou zinco (MARIA et al., 2009) ao suplemento mineral utilizado.

Probióticos são suplementos alimentares que contém microrganismos vivos, que se administrados em quantidades adequadas, produzem efeitos benéficos para a saúde do hospedeiro (animais e seres humanos) (HOLANDA et al., 2008). A eficácia de utilização dos probióticos depende da quantidade e características das cepas de microorganismos utilizados na elaboração do produto a ser utilizado como aditivo alimentar (HOLANDA et al., 2008). A vantagem da utilização de probióticos é a ausência de efeitos secundários, como a seleção de bactérias resistentes (MARTINS et al., 2005). Para os animais de produção, os probióticos não causam efeitos tóxicos e não permanecem como resíduo nos subprodutos destinados ao consumo humano, em quantidades significativas (PARDO; REIS, 2008). Dentre os efeitos benéficos dos probióticos, estão sua utilização como promotores de crescimento aumentando o ganho de peso, a redução do $\mathrm{pH}$ intraluminal do tubo digestivo, minimizando o estresse, impedindo a colonização da mucosa intestinal por bactérias patogênicas e aumentando a resposta imune humoral. Observou-se também um aumento significativo nos títulos de anticorpos antirrábico em bovinos primovacinados contra a raiva, (ARENAS et al., 2009; FERREIRA et al., 2009).

O zinco está envolvido em várias funções no organismo animal (HADDAD; ALVES, 2006), sendo vital para sua sobrevivência(PERES; KOURY, 2006; MARIA et al., 2009). É indispensável para a integridade do sistema imunológico (HADDAD; ALVES, 2006; PERES; KOURY, 2006; MARIA 
et al., 2009), tornando os animais mais resistentes às doenças infecciosas (PERES; KOURY, 2006; MARIA et al., 2009). A deficiência de zinco ocorre quando os animais não ingerem quantidade suficiente desse mineral. Em ruminantes, dietas deficientes causam, em 24 a 36 horas, declínio imediato desse elemento no plasma, provocando a deficiência do mineral (PARDO; REIS, 2008). A absorção intestinal de zinco pode ser reduzida pelo excesso de cálcio na alimentação (TODO et al., 2010). Esse prejuízo na absorção do zinco parece estar relacionado a uma interação negativa entre cálcio e zinco mais pronunciada na presença de fitato (LOBO; TRAMONTE, 2004; PARDO; REIS, 2008).

Dada a importância do probiótico e do zinco na alimentação dos animais, objetivou-se avaliar os efeitos da suplementação do probiótico, com ou sem zinco, sobre a resposta imune humoral em ovinos vacinados com uma única dose de vacina antirrábica.

\section{Material e Métodos}

O experimento foi aprovado pelo Comitê de Ética e Pesquisa, sob protocolo 282/10, pela Universidade do Oeste Paulista, Presidente Prudente, SP e foi desenvolvido nos meses de janeiro a fevereiro de 2009, com o período experimental de 60 dias, no município de Taciba, extremo oeste do estado de São Paulo, Brasil.

Foi analisada a concentração de anticorpos neutralizantes antirrábicos em 45 ovinos, machos mestiços Santa Inês, com idade de aproximadamente 6 meses e divididos aleatoriamente em 3 grupos (15 ovinos por grupo), os quais foram previamente identificados e vermifugados no dia zero do experimento após exame parasitológico de fezes (GORDON; WHITLOCK, 1939). De acordo com avaliação veterinária, os animais apresentavam-se saudáveis e sem deficiência de zinco. Também no dia zero colheram-se amostras das forrageiras dos pastos para avaliar a concentração de zinco no solo, nas pastagens e na água, onde a concentração de zinco das forragens dos piquetes foi determinada por espectrofotometria de absorção atômica em forno de grafite. Ainda no dia zero, o soro dos animais foi analisado para verificar se haviam tido contato com o vírus rábico selvagem e vacinal. Utilizouse a vacina antirrábica (Vencofarma, Laboratórios Vencofarma do Brasil LTDA, Londrina, PR, Brasil) contendo vírus rábico fixo inativado, absorvido pelo gel de hidróxido de alumínio, produzido em cultivo celular. A aplicação foi feita em todos os ovinos numa dose de $2 \mathrm{~mL}$ de vacina por via subcutânea.

As amostras de sangue dos ovinos foram colhidas nos dias 0,30 e 60 . Para isso, os ovinos foram levados no período da manhã para o curral, contidos em tronco de contenção tipo brete e $10 \mathrm{~mL}$ de sangue de cada animal foi colhido por meio de punção da veia jugular em tubos à vácuo sem anticoagulante. Os tubos foram transportados em caixa térmica com gelo para o Hospital Veterinário e após 2 horas centrifugados a 2500 rotações por minuto (rpm) por 10 minutos. As amostras de soro retiradas com pipeta automática foram acondicionadas em tubos plásticos de $1,5 \mathrm{~mL}$ e armazenadas por congelação em freezer a $20^{\circ} \mathrm{C}$ negativo, para determinação do título de anticorpos neutralizantes antirrábicos.

Os títulos individuais de anticorpos neutralizantes foram determinados no Laboratório de Raiva do Instituto Butantan por meio da técnica de soroneutralização em células BHK21 clone 13. Esse teste, baseado no Rapid Fluorescent Focus Inhibition Test - RFFIT (Teste de Inibição de Foco Fluorescente Rápido) (SMITH; YAGER; BAER, 1998) e no Fluorescent Inhibition Microtest - FIMT (ZALAN; WILSON; PUKITIS 1979).

Nos primeiros 30 dias, os animais foram mantidos para adaptação à pastagem, ao qual foram alimentados com capim Aruana em sistema de pastejo extensivo. Os piquetes utilizados pelos grupos de animais eram semelhantes na topografia e composição botânica, onde os animais foram colocados em sistema de rodízio e mantidos sem 
situação de estresse. Todos os piquetes possuíam pasto abundante e sombra. Foram feitos ajustes e estabelecimento do consumo de probiótico adicionado ao sal mineral. A quantidade desse produto adicionado ao sal mineral foi calculada de maneira que cada animal ingerisse cerca de $4 \mathrm{~g}$ por dia, segundo Arenas et al. (2009).

O primeiro grupo, controle (GC) consumiu em média 10 gramas de suplemento mineral/animal/ dia. O segundo grupo (GP), consumiu em média 10 gramas de suplemento mineral adicionado 4 gramas de probiótico/animal/dia e o terceiro grupo consumiu em média 10 gramas de suplemento mineral adicionado 4 gramas de probiótico, e 14,4 $\mathrm{mg}$ de sulfato de zinco/animal/dia adicionado ao probiótico (GPZn).

A determinação do consumo do probiótico/ animal feita no primeiro mês do experimento foi da seguinte maneira: o sal mineral suplementado com o probiótico foi pesado e colocado no cocho e após 24 horas, retirado e pesado novamente. A diferença entre a primeira pesagem e a segunda, dividida pelo número de animais que utilizaram o cocho foi considerada como consumo médio de sal/ovinos durante 24 horas.

O probiótico comercial utilizado (Biologic Plus ${ }^{\hat{a}}$, probiótico, Mart-Mix Produtos Veterinários, Martinópolis, SP, Brasil) foi devidamente registrado e aprovado pelo Ministério da Agricultura e Pecuária e Abastecimento (MAPA), composto por 2.220.000.000 UFC/kg de Lactobacillus, 2.220.000.000 UFC/kg de Bacillus Estreptococusfaecium, 2.220.000.000 UFC/kg de Bifidobacteriumthermoplhilum, $35.000 \mathrm{~g}$ de cálcio, $25.000 \mathrm{~g}$ de enxofre, $20.000 \mathrm{mg}$ de cobalto, 10.000 $\mathrm{mg}$ de iodo e $930.000 \mathrm{~g}$ de veículo.

O suplemento mineral utilizado (Fort Sal ${ }^{\hat{a}}$ da linha ovinos, produzido por Fort Sal Nutrição Animal, Santo Anastácio, SP, Brasil), contendo para cada $\mathrm{Kg}$ de mistura: $140 \mathrm{~g}$ de cálcio, $65 \mathrm{~g}$ de fósforo, $12 \mathrm{~g}$ de enxofre, $100 \mathrm{~g}$ de sódio, $11 \mathrm{~g}$ de magnésio, $1.100 \mathrm{mg}$ de manganês, $2000 \mathrm{mg}$ de ferro, $135 \mathrm{mg}$ de cobalto, $195 \mathrm{mg}$ de iodo, $30 \mathrm{mg}$ de selênio, 20 $\mathrm{mg}$ de níquel e $6000 \mathrm{mg} / \mathrm{g}^{-1}$ de zinco.

Para análise estatística empregou-se o teste de Shapiro-Wilk para avaliar a normalidade dos dados, pelo qual todas as variáveis analisadas foram consideradas como não paramétricas $(\mathrm{p}<0,05)$. A seguir, os títulos sorológicos observados para os grupos $\mathrm{ZnP}, \mathrm{P}$ e C, aos 30 e 60 dias pós-vacinação, foram transformados em escores- $Z$ para determinar a existência de valores atípicos influentes (outliers). Foram classificadas como outliers, as observações com valor de Z > 2,5 (HAIR JUNIOR; ANDERSON; TATHAM, 2005). Para complementar a análise de observações influentes recorreu-se a avaliação gráfica da assimetria dos dados por meio da construção de gráficos do tipo Box-plot. Em razão da existência de múltiplas observações influentes e da falta de normalidade dos dados, optou-se pelo uso de testes não paramétricos para comparações estatísticas. Os títulos sorológicos observados para os três grupos aos 30 e aos 60 dias foram comparados pelo teste não paramétrico de KruskallWallis com contrastes pelo método de Dunn. Os títulos sorológicos dentro de cada grupo, aos 30 e 60 dias pós-vacinação foram comparados pelo teste de Wilcoxon para amostras relacionadas (PAGANO; GAUVREAU, 2010).

Para a partição do Qui-quadrado das tabelas de contingência $2 \times 3$ utilizou-se a fórmula proposta por Kimball (1954), que corresponde ao método de partição desenvolvido por Lancaster (1949) e Irwin (1949). Na partição do Qui-quadrado o nível de significância de $5 \%$ foi ajustado, devido às múltiplas comparações, sendo que para as tabelas $2 \times 3$ adotouse o nível de $2,5 \%(\mathrm{p}<0,025)$.

Dentro de cada grupo, a proporção de animais imunizados contra raiva foi comparada pelo teste Q de Chochran. Todas as análises foram realizadas com auxílio do pacote computacional Bioestat v. 1.0 (AYRES et al., 2007) adotando-se como nível de significância o valor de $5 \%$. 


\section{Resultados e Discussão}

No dia zero, os soros dos animais não apresentaram anticorpos neutralizantes para a raiva, demonstrando que os ovinos não tiveram contato com o vírus rábico selvagem ou vacinal.

De acordo com a análise das concentrações de zinco feitas nas forrageiras dos pastos e na água, foram encontradas $14,3 \mathrm{mg} / \mathrm{g}^{-1}$ de $\mathrm{Zn}$ e $5,43 \mathrm{mg} / \mathrm{g}^{-1}$ de $\mathrm{Zn}$, respectivamente.

A figura 1 compara os títulos soroneutralizantes pós vacinação, direcionados contra o vírus rábico vacinal cepa vírus Pasteur para os grupos de animais tratados com zinco e probiótico aos 30 dias (ZnP30) e aos 60 dias (ZnP60), tratados apenas com probiótico aos 30 dias (P30) e 60 dias (P60) e controles aos 30 dias (C30) e 60 dias (C60). As linhas no interior dos boxes denotam o segundo quartil (50\% dos dadosmediana), as linhas superiores, o terceiro quartil (75\% dos dados) e as inferiores o primeiro quartil (25\% dos dados). As linhas aplicadas indicam os limites dos valores extremos e os pontos externos a elas indicam os outliers.

Figura 1. Títulos soroneutralizantes (eixo y) pós vacinação contra o vírus rábico vacinal cepa vírus Pasteur para os grupos de animais (eixo $\mathrm{x}$ ) tratados com zinco e probiótico aos 30 dias (ZnP30) e aos 60 dias (ZnP60), tratados apenas com probiótico aos 30 dias (P30) e 60 dias (P60) e controles aos 30 dias (C30) e 60 dias (C60).

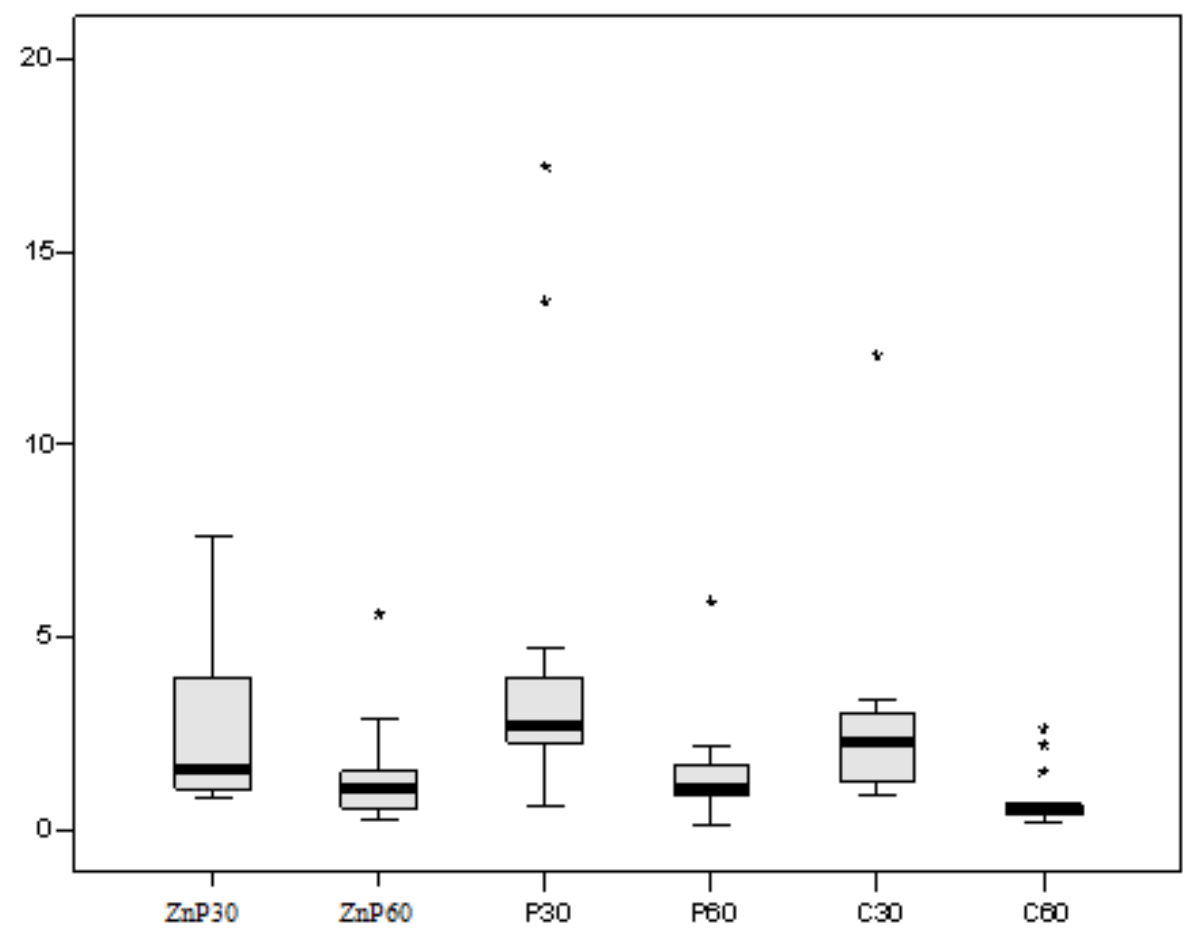

Fonte: Elaboração dos autores.

Não foram observadas diferenças estatísticas entre os três grupos experimentais aos 30 dias e aos 60 dias pós vacinação antirrábica (tabela 1), porém os títulos soroneutralizantes mensurados aos 30 e 60 dias pós vacinação foram diferentes dentro do grupo Zinco + Probiótico $(p=0,0001)$, grupo controle $(\mathrm{p}<0,0001)$ e grupo probiótico $(p=0,0001)$. As proporções de animais considerados imunes aos 30 e 60 dias (títulos $\geq 0,5$ UI) não foram significativamente iguais dentro de cada grupo. 
Tabela 1. Médias e desvios padrão dos títulos de anticorpos soroneutralizantes em UI/mL contra vírus rábico cepa vírus Pasteur mensurados aos 30 e 60 dias pós-vacinação, Presidente Prudente, 2010.

\begin{tabular}{ccc}
\hline Grupo & 30 dias* & 60 dias** \\
\hline Controle (GC) & $3,363 \pm 3,336$ & $0,770 \pm 0,733$ \\
Probiótico (GP) & $4,313 \pm 4,689$ & $1,460 \pm 1,353$ \\
Zinco + probiótico (GPZn) & $2,607 \pm 2,011$ & $1,363 \pm 1,368$ \\
\hline
\end{tabular}

*sem diferenças estatísticas entre os três grupos experimentais $(p=0,3943)$

** sem diferenças estatísticas entre os três grupos experimentais $((p=0,0555)$.

Fonte: Elaboração dos autores.

$\mathrm{Na}$ primeira coluna (30 dias) observa-se de absorção desses minerais (NRS, 1985), que o GP apresenta concentração maior de concordando com estudos feitos por Maria et al. títulos de anticorpos (4,313 $\pm 4,689)$, seguido (2009), que avaliaram o efeito da suplementação pelo GC $(3,363 \pm 3,336)$ e GZnP $(2,607 \pm 2,011)$, em diferentes concentrações de zinco adicionado respectivamente. Essa elevação dos títulos de à mistura mineral de bovinos e Todo et al. (2010) anticorpos pelo GP pode ser justificada pelo efeito que estudaram o efeito do probiótico com ou sem do estímulo ao sistema imunológico (ESPARZA; FRAGOSO, 2010; NOGUEIRA; GONÇALVES, 2011), atribuídos às bactérias ácido láticas (CROSS, 2002; PARDO; REIS, 2008), presentes neste estudo (Lactobacillus e Bifidobacterium). As bactérias em questão potencializam as vacinas, com propriedades moduladoras da resposta imunológica, por aumento da produção de anticorpos, ativação de macrófagos, proliferação de células $\mathrm{T}$ e produção de interferon (ROOS, 2006).

O GZnP apresentou uma menor concentração de títulos de anticorpos comparados ao GP e GC. Este resultado pode indicar uma deficiência na biodisponibilidade do zinco, onde consumido juntamente com o cálcio, provoca deficiência zinco e cálcio na concentração sérica de zinco em ovinos, não observaram influência da resposta imune humoral antirrábica.

Observando a tabela 2, na segunda coluna (60 dias) o GP continuou apresentando maior concentração de títulos de anticorpos $(1,460 \mathrm{Ab} \pm 1,353)$ comparado aos demais grupos, porém o $\mathrm{GZnP}(1,363 \mathrm{Ab} \pm 1,368)$ apresentou uma concentração maior de títulos de anticorpos comparado ao $\mathrm{GC}(0,770 \mathrm{Ab} \pm 0,733)$, contrário à coluna anterior (30 dias), possivelmente por causa da perda da eficiência do GC que não possuía suplemento nutricional ligado ao estímulo do sistema imunológico. O GZnP teve uma menor redução $(1,244 \pm 0,643)$ dos títulos de anticorpos comparados com GP $(2,853 \pm 3,336)$ entre 30 e 60 dias demonstrando ser mais eficiente do que o GP.

Tabela 2. Diferença entre as médias e desvios padrão dos títulos de anticorpos soroneutralizantes em UI/mL contra vírus rábico cepa vírus Pasteur mensurados aos 30 e 60 dias pós-vacinação, Presidente Prudente, 2010.

\begin{tabular}{cccc}
\hline Grupo & 30 dias* & 60 dias** & Diferença entre as médias \\
\hline Controle $(\mathrm{GC})$ & $3,363 \pm 3,336$ & $0,770 \pm 0,733$ & $2,593 \pm 2,603$ \\
Probiótico $(\mathrm{GP})$ & $4,313 \pm 4,689$ & $1,460 \pm 1,353$ & $2,853 \pm 3,336$ \\
Zinco + probiótico $(\mathrm{GPZn})$ & $2,607 \pm 2,011$ & $1,363 \pm 1,368$ & $1,244 \pm 0,643$ \\
\hline
\end{tabular}

*sem diferenças estatísticas entre os três grupos experimentais $(p=0,3943)$

** sem diferenças estatísticas entre os três grupos experimentais $((p=0,0555)$.

Fonte: Elaboração dos autores. 
Houve uma redução das médias (e desvios padrão) dos títulos de anticorpos soroneutralizantes contra o vírus rábico cepa vírus Pasteur, entre os dias 30 e os 60 dias, em todos os grupos estudados, porém, no grupo probiótico, esta redução foi mais acentuada $(2,853 \pm 3,336)$ do que nos grupos controle $(2,593 \pm 2,603)$ e Probiótico + Zinco $(1,244 \pm 0,643)$. Este resultado pode ser explicado porque para este estudo ser realizado, foi utilizado como referência um trabalho feito por Arenas et al. (2009) que avaliou o efeito do probiótico Proenzime ${ }^{\circledR}$ em bovinos primovacinados. A diferença entre os animais de cada estudo (peso, tamanho, quantidade ingerida de matéria seca), além do tipo de probiótico do estudo de Arenas et al. (2009) ser diferente do atual estudo (ambos de composição distintas) podem ter influenciado no resultado.
Assim, como foi feito em bovinos, um estudo deveria ser feito com ovinos a fim de analisar e determinar a quantidade e o tipo de probióticos a ser utilizado para aumentar a resposta imune humoral nesses animais primovacinados.

$\mathrm{Na}$ tabela 3 observa-se uma redução nos títulos de anticorpos dos 30 dias aos 60 dias do experimento. Esses resultados não dispensam a necessidade da aplicação da dose de reforço em ovinos primovacinados, após 30 dias. Após esse período a vacinação deverá ser obrigatória a cada 6 meses, com vacina inativada, conforme preconizado pelo Programa de controle da Raiva em Herbívoros do Instituto Pasteur (FERREIRA et al., 2009; INSTITUTO PASTEUR, 2012a).

Tabela 3. Proporções de animais com títulos soroneutralizantes considerados protetores $(>0,5 \mathrm{UI} / \mathrm{mL})$ mensurados aos 30 e 60 dias pós vacinação em três grupos submetidos a diferentes tratamentos, Presidente Prudente, 2010.

\begin{tabular}{ccccc}
\hline \multirow{2}{*}{ Grupos } & \multicolumn{2}{c}{30 dias } & \multicolumn{2}{c}{60 dias } \\
\cline { 2 - 5 } & $>0,5 \mathrm{UI} / \mathrm{mL}$ & $<0,5 \mathrm{UI} / \mathrm{mL}$ & $8(53,3 \%)$ & $7(46,7 \%)$ \\
\hline Controle (GC) & $15(100 \%)$ & $0(0 \%)$ & $13(86,6 \%)$ & $2(13,4 \%)$ \\
Probiótico (GP) & $15(100 \%)$ & $0(0 \%)$ & $13(86,6 \%)$ & $2(13,4 \%)$ \\
Zinco + probiótico (GPZn) & $15(100 \%)$ & $0(0 \%)$ & $13 \%)$ \\
\hline
\end{tabular}

Fonte: Elaboração dos autores.

Na primeira coluna (30 dias), os animais dos grupos em estudo obtiveram total proteção contra raiva $(100 \%)$, com títulos soroneutralizantes $>0,5 \mathrm{UI} /$ mL. Na coluna seguinte (60 dias), o GP e GPZn apresentaram valores iguais na redução de animais protegidos $(13,4 \%)$, porém o GC reduziu em $46,7 \%$ na proteção de animais protegidos contra o vírus rábico, possivelmente porque o $\mathrm{GC}$ não possuía nenhum suplemento nutricional ligado ao estímulo do sistema imunológico. Não houve diferenças significativas na influência do uso do probiótico com ou sem zinco para o aumento na resposta imune humoral dos ovinos primovacinados, como no trabalho de Ferreira et al. (2009) feito em bovinos; porém, notou-se uma eficiência na suplementação com esses suplementos nutricionais, já que no dia 60 do experimento observou-se somente 2 animais não protegidos contra o vírus rábico nos grupos Zinco + Probióticos e Probióticos, contra 7 animais não protegidos do grupo Controle.

\section{Conclusão}

Às condições em que o experimento foi desenvolvido e de acordo com os resultados obtidos, pode-se concluir que a vacina antirrábica utilizada foi eficiente em induzir a soroconversão e em manter os títulos de anticorpos antirrábicos em ovinos primovacinados por até 30 dias após a vacinação e que as suplementações da mistura mineral com probiótico e probiótico + zinco não fora estatisticamente significantes capazes em melhorar a imunização. 


\section{Referências}

ALBAS, A.; FONTOLAN, L. O.; PARDO, P. E.; BREMER NETO, H.; SARTORI, A. Interval between first dose and booster affected antibody production in cattle vaccinated against rabies. Journal Venomous Animals Toxins Including Tropical Diseases, Botucatu, v. 12, n. 3, p. 476-86, 2006.

ARENAS, S. E.; REIS, L. S. L. S.; FRAZATTIGALLINA, N. M.; FUJIMURA, S. H.; BREMER NETO, H.; PARDO, P. E. Probiotic increase the antirabies humoral immune response in bovine. Archivos Zootecnia, Cordoba, v. 58, n. 224, p. 733-6, 2009.

AYRES, M.; AYRES JÚNIOR, M.; AYRES, D. L.; SANTOS, A. A. S. BIOESTAT: aplicações estatísticas nas áreas das ciências biomédicas. Belém: Ong Mamiraua, 2007. 364 p.

BRASIL. Ministério da Agricultura, Pecuária e Abastecimento. Controle da raiva dos herbivoros: manual técnico 2009. Brasília: Mapa/ACS, 2009. 124 p.

CROSS, M. Microbes versus microbes: immune signals generated by probiotic lactobacilli and their role in protection against microbial pathogens. FEMS Immunology and Medical Microbiology, v. 34, n. 4, p. 245-53, 2002.

ESPARZA, J. A. R.; FRAGOSO, L, R. ¿Qué sabe Ud. acerca de lós probióticos? Revista Mexicana de Ciencencias Farmacéuticas, México, v. 41, n. 1, p. 60-3, 2010.

FERREIRA, L. A.; PARDO, P. E.; FRAZATTIGALLINA, N. M.; MOURÃO-FUCHES, R. M.; VENTINI, D. C.; KRONKA, S. N.; ARENAS, S. E.; REIS, L. S. L. S. Avaliação da vacinação antirrábica e da suplementação com probiótico na resposta imune humoral em bovinos. Semina: Ciências Agrárias, Londrina, v. 30, n. 3, p. 655-660, 2009.

GORDON, H. M.; WHITLOCK, A. V. A new technique for counting nematode eggs in sheep feces. Journal of Council of Science and Industry Research, Melbourne, v. 12, n. 1, p. 50-52, 1939.

HADDAD, C. M.; ALVES, F. V. Novos conceitos e tecnologias na suplementação mineral de bovinos. In: CONGRESSO LATINO AMERICANO DE NUTRIÇÃO ANIMAL, 2., 2006. Anais... São Paulo: [s.n], 2006. p. $1-9$.

HAIR JUNIOR, J. F.; ANDERSON, R. E.; TATHAM, R. L. Análise multivariada de dados. 5. ed. Porto Alegre: Bookman, 2005. 593 p.
HOLANDA, L. B.; ANTUNES, A. E.; DEL SANTO, R.; MUNIZ, V. O. Conhecimento sobre probióticos entre estudantes de uma instituição de ensino superior. Revista Acadêmica Digital do Grupo POLIS Educacional, Jaguariuna, v. 4, n. 5, p. 225-39, 2008.

INSTITUTO PASTEUR. Ações em áreas epidêmicas: imunização. São Paulo: [s.n], 2012a. Disponível em: <http: $\quad$ www.pasteur.saude.sp.gov.br/informacoes/ manuais/manual_1/manual_14.htm $>$. Acesso em: $19 \mathrm{fev}$. 2012.

Raiva dos herbivoros. São Paulo: [s.n], 2012b. Disponível em: <http://www.pasteur.saude.sp.gov.br/ informacoes/informacoes_03.htm>. Acesso em: 1 abr. 2012.

IRWIN, J. O. A note on the subdividsion of \#2 into components. Biometrika, v. 36, n. 1-2, p. 130-134, jun. 1949.

KIMBALL, A. W. Short-cut formulas for the exact partition of \#2 in contingency tables. Biometrics, Washington, v. 10, n. 4, p. 452-8, 1954.

LANCASTER, H. O. The derivation and partition of \#2 in certain discrete distributions. Biometrika, v. 36, n. 1-2, p. 117-129, jun. 1949.

LOBO, A. S.; TRAMONTE, V. L. C. Efeitos da suplementação e da fortificação de alimentos sobre a biodisponibilidade de minerais. Revista de Nutrição, Campinas, v. 17, n. 1, p. 107-13, 2004.

MARIA, E. K.; PARDO, P. E.; FRAZATTI-GALLINA, N. M.; PAOLI, R. L.; MOURÃO-FUCHES, R. M. REIS, L. S. L. S. Efeito com a suplementação com zinco na resposta immune humoral antirrábica em bovinos. Archivos de Zootecnia, Córdoba, v. 58, n. 1, p. 605-608, 2009.

MARTINS, F. S.; BARBOSA, F. H. F.; PENNA, F. J.; ROSA, C.A.; NARDI, R. M. D.; NEVES, M. J.; NICOLI, J. R. Estudo do potencial probiótico de linhagens de Saccharomyces cerevisiae através de testes in vitro. Revista de Biologia e Ciências da Terra, João Pessoa, v. 5, n. 2, p. 1-13, 2005.

MENTEN, J. F. M. Aditivos alternativos na produção de aves: probióticos e prebióticos. In: REUNIÃO DA SOCIEDADE BRASILEIRA DE ZOOTECNIA, 38., 2001, Piracicaba. Anais... Piracicaba: Sociedade Brasileira de Zootecnia, 2001. p. 141-157.

NOGUEIRA, J. C. R.; GONÇALVES, M. C. R. Probiotics in allergic rhinitis. 2011. Brazilian Journal of Otorhinolaryngol, São Paulo, v. 77, n. 1, p. 129-34, 2011. 
NUTRIENT REQUIREMENTS OF SHEEP- NRS. Minerals. 6. ed. Washington: National Academy Press, 1985. p. 11-22.

PAGANO, M.; GAUVREAU, K. Principios de bioestatística. 2. ed. São Paulo: Pioneira Thomson Learneing, 2010. 506 p.

PARDO, P. E.; REIS, L. S. L. S. Nutrientes e nutracêuticos em grandes animais. In: ANDRADE, S. F. Manual de terapêutica veterinária. 3. ed. São Paulo: Rocha, 2008. p. 808-814.

PERES, P. M.; KOURY, J. C. Zinco, imunidade, nutrição e exercício. Revista Ceres, Viçosa, v. 1, n. 1, p. 9-18, 2006.

RODRIGUES, O; SOUSA, M. R.; DUARTE, M. H. S.; CASTRO, R. S.; MEDEIROS, P. L. Avaliação da influência de levamisole sobre padrões de proteínas e leucograma em caprinos (Capra hircus) nativos da região semi-árida nordestina. Agropecuária Científica no SemiÁrido, Patos, v. 1, n. 1, p. 50-58, 2005.

ROOS, T. B. Efeito de Saccharomyces boulardii e Bacillus cereus var. toyoi na resposta imune humoral de cordeiros vacinados contra Escherichia coli e Herpes Vírus Bovino-5. 2006. Dissertação (Mestrado em Veterinária) - Faculdade de Veterinária. Universidade Federal de Pelotas, Pelotas.
SCHEFFER, K. C.; CARRIERI, M. L.; ALBAS, A.; SANTOS, H. C.; PIRES; KOTAIT, I.; ITO, F. H. Vírus da raiva em quirópteros naturalmente infectados no Estado de São Paulo, Brasil. Revista de Saúde Pública, São Paulo, v. 41, n. 3, p. 389-395, 2007.

SMITH, J. S.; YAGER, P. A.; BAER, G. M. A rapid fluorescent focusinhibition test (RFFIT) for determining rabies virusneutralizing antibodies. In: MESLIN, F. X.; KAPLAN, M. M.; KOPROWISKI, H. (Ed.). Laboratorytechiniques in rabies. Geneva: WHO, 1998. p. 181-192.

TERRASSI, F. M.; FERRES, M. H. M.; CALVO, L. A.; BREMER-NETO, H.; PARDO, P. E. Efeito do probiótico proenzime ${ }^{\circledR}$ no peso de bovinos da raça nelore criados em regime de pasto. Colloquium Agrariae, Presidente Prudente, v. 6, n. 2, p. 52-56, 2010.

TODO, R. Z.; DONADELI, J. P. P.; SARAIVA, H. F. R. A.; PENHA, L. A. C.; PARDO, P. E.; GIUFFRIDA, R.; GENARO, S. C. Efeito do probiótico com ou sem zinco e cálcio na concentração sérica de zinco em ovinos. Colloquium Agrariae, Presidente Prudente, v. 6, n. 2, p. 57-61, 2010.

WHO. Expert committee on rabies. Geneva: [s.n], 1992. 92 p. (Technical report series, 824).

ZALAN, E.; WILSON, C.; PUKITIS, D. A microtest for the quantitative of rabies virus neutralizing antibodies. Journal of Biological Standardization, New York, v. 7, n. 3, p. 213-220, 1979. 
